\title{
Conversion of Used Glass Bottles to Porous Materials by Using Hydrothermal Technique
}

\author{
Kazumichi Yanagisawa $^{1 *}$, Ningzhong Bao ${ }^{1}$, Misato Kariya ${ }^{1}$, Ayumu Onda ${ }^{1}$, Koji Kajiyoshi ${ }^{1}$, \\ Zully Matamoras-Veloza ${ }^{2}$, Juan Carlos Rendón-Angeles ${ }^{3}$ \\ ${ }^{1}$ Research Laboratory of Hydrothermal Chemistry, Kochi University, Kochi 780-8520, Japan \\ ${ }^{2}$ Instituto Tecnológico de Saltillo, Facultad de Metal-Mecánica, Saltillo, Coah. 25400, México \\ ${ }^{3}$ Centro de Investigación y Estudios Avanzados del IPN, Saltillo, Coah. 25900, México
}

\begin{abstract}
Conversion of used glass bottles to porous materials was investigated for recycling of used glasses. The ordinary method to prepare porous materials from glass needs vesicants such as calcium carbonate and silicon carbide that decompose at high temperatures to produce gas, and the gas is trapped in softened glass to form pores. In this study, used glass bottles were converted to porous plates by using hydrothermal technique. First, a glass powder is hydrothermally treated at low temperatures, so that water diffuses into the glass structure. Water is released as vapor to form pores in the softened glass, when the hydrothermally treated glass powder is heated at high temperatures. Thus, this process gives porous materials with a fine structure including closed pores at lower temperature than the ordinary method. The effects of hydrothermal treatment and calcination conditions on bulk density of the resulted porous materials were investigated with a small scale to determine the conditions to get light porous materials. Finally, porous plates $(45 \times 45 \times 3$ $\mathrm{cm}^{3}$ in size) with density of $0.45 \mathrm{~g} / \mathrm{cm}^{3}$ were produced by hydrothermal treatment of the glass powder at $180^{\circ} \mathrm{C}$ in a large autoclave with inside volume of $2.5 \mathrm{~m}^{3}$, followed by calcination at $800^{\circ} \mathrm{C}$ in a continuous heater with $18 \mathrm{~m}$ in length.
\end{abstract}

Keywords: used glass, recycling, porous materials.

\section{INTRODUCTION}

It has been well recognized that the material recycling is important for a sustainable development $[1,2]$. We have been interested in recycling of used glass bottles. The total production weight of glass bottles in Japan was 1,550,000 ton in 2004 [3]. In Japan, these glass bottles are separated into three colors, transparent, brown and others, and recovered for recycling. Their recycled amount was 320,478 ton in 2004 [4]. The used glass bottles were mainly (69\%) used as a raw material to produce new bottles, and the remainder $(31 \%)$ was converted to other materials. It is easy to produce new bottles from separated transparent and brown glass bottles, but not from the bottles with mixed colors. In order to increase the recycled amount of the bottles with mixed colors, they were used for production of heat insulator, aggregates for concrete and asphalt, base and subbase filler materials, and cement constituent [5]. In this study, we developed a new technique to recycle the used glass bottles with mixed colors by conversion to porous plates.

Porous materials have been produced from glass by the ordinary method, in which glass powder was mixed with vesicants such as calcium carbonate and silicon carbide, and heated at high temperatures. The vesicants decompose at high temperatures to produce gas, and the gas is trapped in softened glass to form pores. It is important that gas is released from vesicants after glass is softened. In our new method, glass powder is first hydrothermally treated at low temperatures and then calcined at high temperatures. Water diffuses into glass structure by hydrothermal treatments, 
and is released as vapor to form pores in the softened glass when the hydrothermally treated glass is heated at high temperatures. Water incorporated into the glass structure by hydrothermal treatments acts as a vesicant. In this method, each glass particle after hydrothermal treatment can foam by heat treatment al low temperature in comparison with the ordinary method. Figure 1 schematically illustrates the procedures.
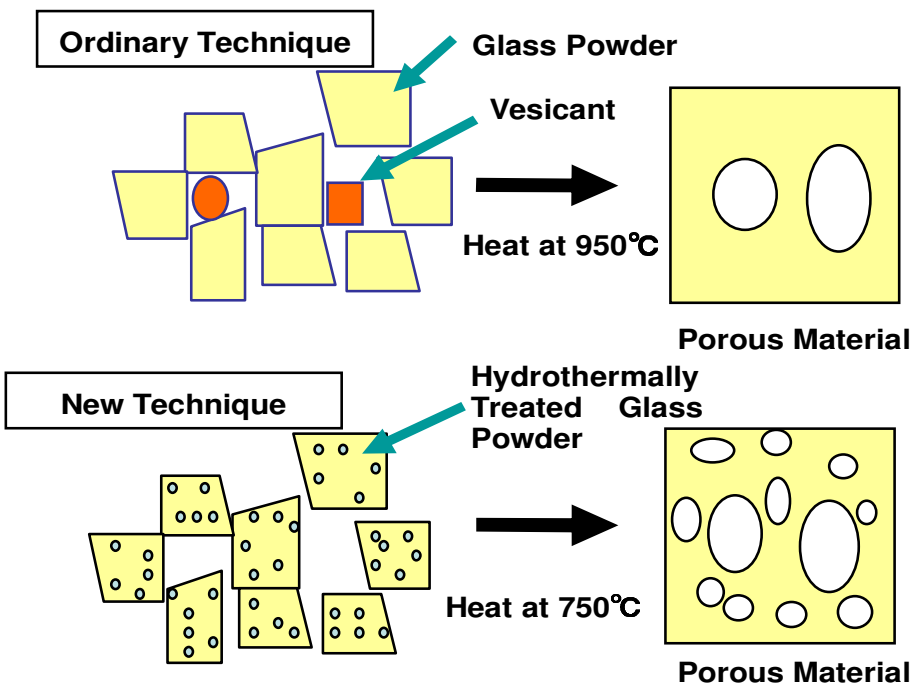

Figure 1. The techniques for preparation of porous materials from glass powders

\section{EXPERIMENTAL}

In order to determine the foaming behavior, experimets with a small scale were conducted in the laboratory. The starting glass powder was prepared by crashing the used glass bottles followed by thieving to be under $250 \mu \mathrm{m}$. The glass powder was hydrothermally treated in a Teflon lined autoclave, varying amount of water $\left(5-40\right.$ mass \%), temperature $\left(140-220^{\circ} \mathrm{C}\right)$ and time $(6-48$ hours $)$. The hydrothermally treated glass powder was softly packed into a small stainless steel tube $(34 \mathrm{~mm}$ in inner diameter and $10 \mathrm{~mm}$ in height), inserted into a preheated furnace, and heated at $650-900^{\circ} \mathrm{C}$ for 1-60 minutes. The calcination time was defined as a time period after the hydrothermally treated powder was placed in the preheated furnace. After the scheduled heat treatment, the glass powder foamed and expanded to the upper direction from the tube. The part bulged out the tube was cut off, and bulk density of the porous materials was calculated form inside volume of the tube and weight of foamed material filled in the tube. The crystalline phases of the samples were determined by powder X-ray diffraction (XRD) and scanning electron microscopic observation (SEM) was conducted on the glass powders and fracture surfaces of the foamed materials to observe morphology and pore structures.

For the preparation of large porous materials, commercially available glass powder (particle size under $590 \mu \mathrm{m}$ ) produced by milling of used glass bottles was used. The hydrothermal treatment was conducted for the glass powder of $320 \mathrm{~kg}$ at $183^{\circ} \mathrm{C}$ for 10 hours in saturated vapor in an autoclave (Tokai Concrete Ind. Co., LTD.) with inner volume of $2.5 \mathrm{~m}^{3}$. The hydrothermally treated glass powder was placed on stenless mesh belt and heated at $800^{\circ} \mathrm{C}$ for 36 minutes in a continuous furnace (Toyo System Plant Co., Ltd., Japan) with width $1 \mathrm{~m}$ and length $20 \mathrm{~m}$. After heated in the 
continuous furnace, the foamed materials were immediately moved to a furnace at $450^{\circ} \mathrm{C}$ and kept the temperature for 4 hours.

\section{RESULTS AND DISCUSSION}

When the glass powder was hydrothermally treated with 15 mass $\%$ of water at different temperatures for 12 hours, some crystalline phases started to be formed at $140^{\circ} \mathrm{C}$, and their amount increased with the increase in reaction temperature. By calcination of the hydrothermally treated glass powders for a very short time, these crystalline phases disappeared and changed to be amorphous. These crystalline phases must be hydrates formed by reaction of the glass with water under hydrothermal conditions. When the hydrothermally treated glass powders were heated at high temperatures beyond $750^{\circ} \mathrm{C}$ for a long time over 30 minutes, other crystalline phases mainly composed of $\mathrm{Na}_{2} \mathrm{Ca}_{3} \mathrm{Si}_{6} \mathrm{O}_{16}$ were formed in the amorphous phase.

By fixing the calcination conditions at $750^{\circ} \mathrm{C}$ for 30 minutes, hydrothermal conditions (amount of water, temperature, and time) were systematically changed to determine the conditions to give porous materials with low density. When the glass powder was treated at $180^{\circ} \mathrm{C}$ for 12 hours varying amount of water, porous materials with lowest density were obtained at $15-20$ mass $\%$ of water. Figure 2 shows fracture surfaces of the porous materials prepared from the hydrothermally treated glass powder with different amount of water. The size of pores in the porous materials was small when the glass powder was hydrothermally treated with a small or large amount of water (Fig. 2 (a), (c)). The glass hydrothermally treated with water of 15 mass $\%$ gave larger pores up to $500 \mu \mathrm{m}$ (Fig. 2(b)), which was agreed with the density change.

When a small quantity of water is added in the autoclave, the amount of water diffused into glass structure must be limited. With a large amount of water, the glass powder was in liquid water, and the glass reacted with water to form a large amount of crystalline phases which could not foam by calcination. The treatment of the glass in vapor phase was important to get low density.
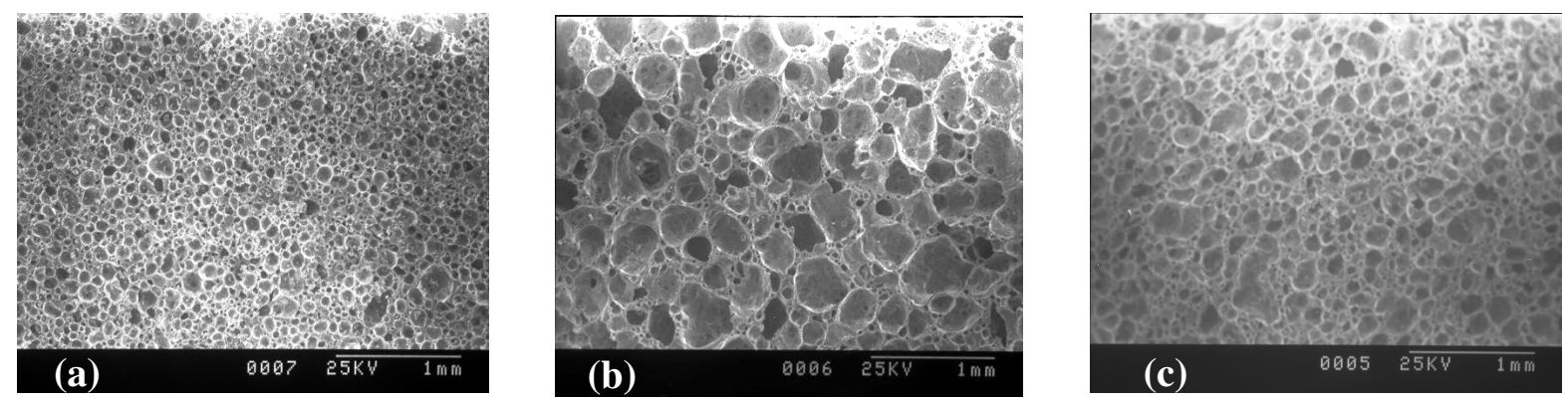

Figure 2. SEM photographs of fracture surfaces of porous materials obtained from hydrothermally treated glasses at $180^{\circ} \mathrm{C}$ for 12 hours with different amount of water, (a) 10 mass \%, (b) 15 mass \%, and (c) 40 mass $\%$. Hydrothermally treated glasses were calcined at $750^{\circ} \mathrm{C}$ for 30 minutes.

The hydrothermal temperature that gave the lowest density was determined to be $200-220^{\circ} \mathrm{C}$ by treatment for 12 hours with water of 15 mass $\%$. The reaction time had a large effect on density. The porous material with lowest density of $0.26 \mathrm{~g} / \mathrm{cm}^{3}$ was obtained by hydrothermal treatment for 12-14 hours at $200^{\circ} \mathrm{C}$ with water of 15 mass $\%$. The other experiment showed that the hydrothermal treatments of cubic shaped glass bocks at $200^{\circ} \mathrm{C}$ in saturated vapor phase first gave amorphous reaction layers and the layer crystallized by further hydrothermal treatment. Thus, it is important to select the hydrothermal conditions to get a large amount of water diffused glass phase for preparation of porous materials with low density. 
The hydrothermally treated glass powder at $200^{\circ} \mathrm{C}$ with water of 15 mass\% for 12 hours was heated under different calcination conditions. When calcination time was less than 10 minutes at $750^{\circ} \mathrm{C}$, particles did not stick to each other and compacts were not obtained. After 10 minutes, porous materials were obtained and their density decreased with the increase in time up to 30 minutes. The longer calcination time resulted in slight increase in density. When the calcination time was fixed to 30 minutes, the calcination at $850^{\circ} \mathrm{C}$ gave the lowest density $\left(0.19 \mathrm{~g} / \mathrm{cm}^{3}\right)$. The pores, however, became large beyond $1 \mathrm{~mm}$ in size and the mechanical strength remarkably decreased. At low temperatures below $700^{\circ} \mathrm{C}$, the samples remained to be powders. The optimum calcination temperature is in the range of 750 $800^{\circ} \mathrm{C}$.

An large autocalve and a continuous furnace were used to prepare large porous materials with an industrial scale. The hydrothermal treatment was conducted at $183^{\circ} \mathrm{C}$ for 10 hours in saturated vapor and the calcination at $800^{\circ} \mathrm{C}$ for 36 minutes. They had high machinability due to their fine microstructure, so that it was very easy to shape them into plates. In this study, plates with $45 \times 45 \times 3 \mathrm{~cm}^{3}$ in size were produced as shown in

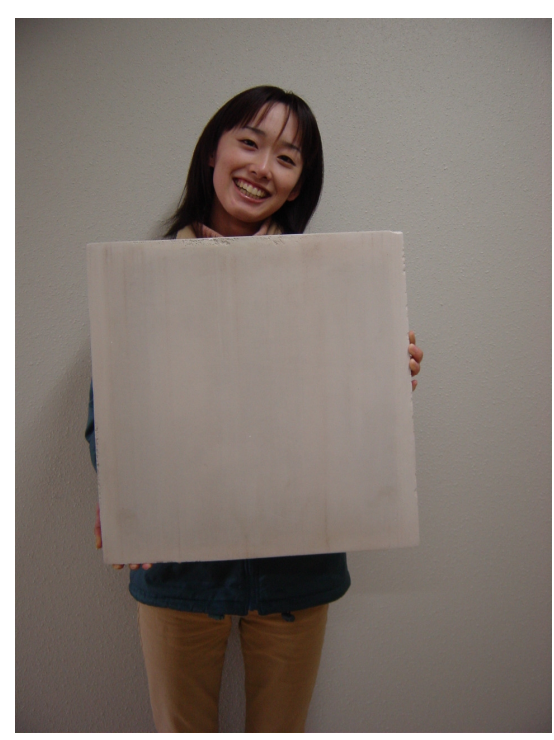

Figure 3. A porous plate produced from used glass bottles by hydrothermal treatment at $183^{\circ} \mathrm{C}$ for 10 hours, foolowed by $800^{\circ} \mathrm{C}$ for 36 minutes.

Figure 3. The plates had following properties as average values; bulk density $0.45 \mathrm{~g} / \mathrm{cm}^{3}$, compressive strength $140 \mathrm{~kg} / \mathrm{cm}^{2}$, bending strength $55 \mathrm{~kg} / \mathrm{cm}^{2}$, thermal conductivity $0.18 \mathrm{~W} / \mathrm{mK}$, and line expansion coefficient $5.8 \times 10^{-6} / \mathrm{K}$. Lighter porous plates may be produced by optimizing the hydrothermal treatment conditions.

\section{CONCLUSIONS}

A new technique involving hydrothermal treatment followed by calcination was developed to recycle used glass by conversion to porous materials. Porous plates were successfully produced from colored used glass bottles by hydrothermal treatment at $183^{\circ} \mathrm{C}$ for 10 hours, followed by heat treatment at $800^{\circ} \mathrm{C}$ for 36 minutes. The plates had a fine structure with some closed pores and floated on water. These plates may be useful as a light weighted board for the void slab system, thermal insulators, sound and water absorbents, floats to form floating islands, and so on..

\section{REFERENCES}

1. P. Kavouras, Ph. Komniou, K. Chrissafits, G. Kaimakamis, S. Kokkou, K. Paraskevopoulos, Th. Karakostas: J. Eur. Ceram. Soc., Vol. 23 (2003), p. 1305.

2. M. Ogura, I. Astuti, T. Yoshikawa, K. Morita, H. Takahashi: Ind. Eng. Chem. Res., Vol. 43 (2004) p. 1890.

3. Home page of The Japan Containers And Packing Recycling Association, www.jcpra.or.jp/data/index.html

4. Home page of Glass Bottle Recycling Promoter Association, www.glass-recycle-as.gr.jp

5. K. Sobolev: Am. Ceram. Soc. Bull., Vol. 82 (2003) p. 9501. 